\title{
Queimaduras: visão holística acerca do manejo cirúrgico
}

\author{
Burns: holistic view of surgical management \\ Quemaduras: visión holística del tratamiento quirúrgico
}

Sarah Menezes Gashti ${ }^{*}$, Carlos Eduardo da Silva Isidoro², Gabriela Moreira Lima ${ }^{3}$, Gabriella Paschoal Trombeli ${ }^{4}$, Letícia Nogueira Carvalho Costa de Araújo ${ }^{1}$, Lilian Caiafa Ferreira Machado ${ }^{5}$, Marcela Vasconcelos Montenegro ${ }^{6}$, Mariana Vanon Moreira ${ }^{7}$, Sara Oliveira Reis ${ }^{1}$, Pablo Juarez Calieron ${ }^{8}$.

\section{RESUMO}

Objetivo: Revisar e evidenciar alguns dos mais relevantes tipos de tratamentos para queimaduras dentro da cirurgia plástica. Revisão Bibliográfica: As queimaduras são lesões que acometem o tegumento corporal, e apresentam múltiplas causas, sendo estas: térmicas, químicas, radioativas, elétricas ou por fricção. Além disso, essas também podem ser classificadas quanto à profundidade da injúria. Dessa forma, é de suma importância o conhecimento acerca da fisiopatologia das queimaduras, com objetivo de determinar a escolha do procedimento cirúrgico ideal para cada contexto clínico, a fim de garantir recuperação parcial ou total da área afetada. Dentre os manejos cirúrgicos e multidisciplinares, menciona-se respectivamente: desbridamento cirúrgico, fasciotomia, escarotomia, excisão, enxertos de pele, substitutos cutâneos, acompanhamentos psicológico, terapêutico e cosmiátrico. Considerações finais: Evidencia-se a importância distinguir os mais relevantes tipos de tratamentos para queimadura, com o objetivo de adequar cada terapêutica à condição clínica do paciente e, com isso, proporcionar melhor prognóstico e restituição funcional e esteticamente do segmento acometido.

Palavras-chave: Queimaduras, Pele artificial, Desbridamento.

\section{ABSTRACT}

Objective: To review and to evidence some of the most relevant types of treatment for burns inside the plastic surgery. Bibliographic review: Burns are injuries that attack the tissue, and can be caused by many sources, including: heat, chemicals, radiation, electrical or friction. Furthermore, they are classified for the level of damage. Therefore, it is mission-critical to have knowledge about the physiopathology of burns injuries, with the intention to determine the ideal surgical treatment, to assure total or partial recovery of the damaged area. Between the possibilities of surgical and multidisciplinary management are: surgical debridement, fasciotomy, escharotomy, excision, skin grafts, permanent or temporary skin substitutes, psychological, therapeutic and cosmiatric accompaniments. Final considerations: It becomes more evident the importance of discerning the possibilities of treatments for burns injuries, with the intention to follow the best therapeutic choice according to the clinic condition of the patient, and to provide the best prognostic and functional and aesthetic restitution of the affected segment.

Key words: Burns, Artificial skin, Debridement.

\footnotetext{
${ }^{1}$ Universidade do Planalto Central Apparecido dos Santos (UNICEPLAC), Brasília - DF.

*E-mail: sarahgashti@hotmail.com

2 Universidade Cidade de São Paulo (UNICID), São Paulo - SP.

${ }^{3}$ Faculdade de Ciências Humanas, Econômicas e da Saúde (FAHESA/ITPAC), Palmas - TO.

${ }^{4}$ Centro Universitário Estácio de Ribeirão Preto (ESTÁCIO RIBEIRÃO PRE), Ribeirão Preto - SP.

${ }^{5}$ Pontifícia Universidade Católica de Minas Gerais (PUC MINAS), Betim - MG.

${ }^{6}$ Universidade de Pernambuco (UPE), Recife - PE.

${ }^{7}$ Faculdade de Ciências Médicas e da Saúde de Juiz de Fora (FCMS), Juiz de Fora - MG.

${ }^{8}$ Universidade Luterana do Brasil (ULBRA), Canoas - RS.
} 


\section{RESUMEN}

Objective: Hacer una revisión y evidenciar algunos de los más relevantes tipos de tratamientos para quemaduras dentro de la cirugía plástica. Revisión bibliográfica: Las quemaduras son lesiones que afectan el tegumento corporal, y tienen múltiples causas, las cuales son: térmicas, químicas, radioactivas, eléctricas o por fricción. Además, estos también se pueden clasificar según la profundidad de la lesión. Por lo tanto, el conocimiento sobre la fisiopatología de las quemaduras es extremadamente importante, con el fin de determinar la elección del procedimiento quirúrgico idóneo para cada contexto clínico, para garantizar la recuperación parcial o total de la zona afectada. Entre los manejos quirúrgicos y multidisciplinarios, se mencionan respectivamente: desbridamiento quirúrgico, fasciotomía, escarotomía, escisión, injertos de piel, sustitutos de piel, seguimientos psicológicos, terapéuticos y cosmiátricos. Consideraciones finales: Es evidente la importancia de distinguir los tipos de tratamientos más relevantes para las quemaduras, con el objetivo de adecuar cada terapia a la condición clínica del paciente y, así, proporcionar un mejor pronóstico y restitución funcional y estética del segmento afectado.

Palabras clave: Quemaduras, Piel artificial, Desbridamiento.

\section{INTRODUÇÃO}

Queimaduras são ferimentos que intercorrem no tegumento corporal, podendo ser causadas pela interação direta com fontes térmicas, químicas, radioativas, correntes elétricas e fricção; esta ocorrência é capaz de contatar níveis mais profundos, como músculos, tendões e ossos, sendo apto de provocar avarias fragmentais ou integrais da pele. Além disso, em vítimas de queimaduras, o risco de infecções é alto, juntamente à sepse e falência múltipla de órgãos, possibilitando o óbito do paciente (CONITEC, 2018; ROWAN MP, et al., 2015).

De acordo com a profundidade do trauma é possível classificá-las em primeiro grau, as quais atingem as porções mais superficiais da pele, sendo evidente eritema, dor no local e não há formação de bolhas. As de segundo grau são divididas em superficiais e profundas; nas superficiais são atingidas apenas a epiderme e derme, manifestando dor, vermelhidão, bolhas e possibilidade de formação de leves cicatrizes. Nas profundas são alcançadas a derme reticular, são dolorosas e formam cicatrizes em decorrência da perda da derme. Caso uma infecção aconteça, essa pode se desenvolver em uma queimadura de terceiro grau, aquela em que toda a derme e tecido cutâneo subjacente são destruídos. Por último, as de quarto grau, são lesões profundas que se estendem para os ossos, tendões e músculos, são potencialmente fatais; devido à total destruição das terminações nervosas, não são dolorosas (CARBONI RM, et al., 2019; CONITEC, 2018).

Calcula-se que no Brasil aconteçam cerca de 1 milhão de acidentes de queimaduras anualmente, destes, 100 mil vítimas recorrem ao atendimento hospitalar, visto que 2.500 morrerão direta ou indiretamente por razões relativas às lesões. Essa fatalidade atinge todas as idades, contudo inúmeros estudos expressam que a queimadura é um dos principais motivos de acidentes não intencionais em crianças e adolescentes, sendo a segunda causa de morte acidental na infância (CONITEC, 2018).

A importância de um tratamento bem-feito é levar o paciente a uma recuperação funcional e estética, sem que haja a formação de sequelas, como cicatrizes hipertróficas ou queloides. Para que o tratamento seja eficaz, é necessário o conhecimento a respeito das queimaduras e seu processo de cura. A finalidade do tratamento das queimaduras superficiais é a atenuação da dor, restauração dos vasos superficiais e estímulo à epitelização; já nas lesões profundas a terapêutica integra a manutenção da perfusão tissular e preservação de tecidos viáveis, com remoção prévia do tecido necrótico e cobertura do local (DALMEDICO MM, et al.,2016; WURZER P, et al., 2016).

O avanço dos tratamentos nesta área foi muito relevante nos últimos anos. A mortalidade de pacientes gravemente e amplamente queimados diminuiu expressivamente em virtude das melhorias no manejo de infecção, ressuscitação precoce, melhores abordagens cirúrgicas e outros tratamentos fundamentados na melhor compreensão da fisiopatologia da queimadura. Apesar da evolução contínua no aprimoramento de 
substitutos da pele, nenhum se ressalta como "padrão ouro" ou ideal; levando-se em conta essa gama de substitutos, os médicos atualmente podem optar entre uma diversidade de produtos e técnicas com características distintas que se adéquam conforme as condições específicas do quadro do paciente, levandose em consideração idade da vítima, extensão, profundidade, área afetada, além da eficácia do curativo, entre outros (LIU HF, et al., 2017; WURZER P, et al., 2016).

Diante do exposto, por se tratar de um tema relevante e atual, a importância desse estudo está no potencial de auxiliar profissionais da saúde a agregarem conhecimento acerca de tratamentos eficazes, como: desbridamento cirúrgico, fasciotomia, escarotomia, excisão, enxertos de pele, substitutos cutâneos, tratamento multidisciplinar e cosmiatria. Sendo assim, define-se como objetivo desta revisão evidenciar alguns dos mais relevantes tipos de tratamentos para queimadura realizados por Cirurgiões Plásticos.

\section{REVISÃO BIBLIOGRÁFICA}

\section{Avaliação}

A queimadura atinge diversos órgãos; sobretudo, o mais acometido é o tecido de revestimento humano, a pele. A pele é classificada como o maior órgão do corpo humano e desempenha importantes funções, entre as quais mencionam-se: manutenção termorreguladora e metabólica; proteção contra agentes físicos, químicos ou infecciosos; excreção de toxinas e de resíduos metabólicos; e a função sensitiva, responsável pelo sentido do tato, da temperatura e da dor. Com isso, por ser o órgão mais acometido, e a depender da causa, da profundidade e da extensão da área queimada, as funções por ele desempenhadas são acometidas, de modo a comprometer a homeostase corporal. Dessa forma, diversos fatores colaboram na orientação e no manejo adequado das queimaduras (FILHO AG, et al., 2012).

Primeiramente, em relação às causas, as queimaduras podem ser ocasionadas por agentes térmicos, químicos, radioativos, elétricos e por fricção. Dentre estas, a térmica é a mais comum. Quanto à gravidade de queimaduras químicas, aquelas de origem alcalina são mais graves por penetrarem mais na pele e por causar necrose de liquefação; enquanto as ácidas penetram menos por causar uma lesão de coagulação (necrose de coagulação). As elétricas carecem de maior atenção médica, pois apesar de apresentarem pequenas feridas de entrada e de saída, estas podem causar lesões extensas aos órgãos internos ou lesões traumáticas associadas. Com isso, fica evidente que as diversidades de lesões de queimaduras podem causar dano total ou parcial à pele e seus anexos ou até mesmo atingir camadas mais profundas (EVERS LH, et al., 2010; SCHAEFER TJ e SZYMANSKI KD, 2019).

Um dos principais fatores a serem considerados ao avaliar a pele queimada é extensão da injúria, em que é estimado e calculado percentualmente a área total da superfície corporal queimada por meio de dois principais métodos: A regra dos nove e o gráfico de Lund e Browder. A regra dos nove normalmente é a mais utilizada, em que se conferido o valor 9 aos segmentos corporais, a cabeça representa $9 \%$, cada um dos braços é $9 \%$, a parte anterior do tórax e abdômen $18 \%$, a parte posterior do tórax e as costas $18 \%$, cada perna é $18 \%$ e o períneo é $1 \%$. O Gráfico de Lund e Browder é mais preciso e utilizado com crianças, nele cada braço representa 10\%, o tronco anterior e tronco posterior são cada um 13\% (FILHO AG, et al., 2012; SCHAEFER TJ e SZYMANSKI KD, 2019).

A classificação conhecida por determinar os graus do trauma é estabelecida a partir da profundidade dele. As lesões de primeiro grau são aquelas que acometem a região mais superficial da pele, a epiderme, onde é apresentado rubor/eritema, dor local, sem a formação de bolhas. As de segundo grau são divididas em superficiais e profundas. A superficial atinge apenas a epiderme e a derme papilar (camada mais externa da derme); com isso, é manifestada dor, vermelhidão, bolhas e possíveis cicatrizes. A de segundo grau profundo atinge todos os tecidos anteriores e a derme reticular (revestimento mais externo da derme); sendo bastante dolorosa, com formação de cicatrizes, em consequência da perda total da derme. As injúrias de $3^{\circ}$ grau acometem todo tecido cutâneo e a gordura subcutânea subjacente; com isso, a pele apresenta coloração branca, marrom ou carbonizada, sendo circundadas por bolhas e podem manifestar ou não a dor. Por fim, as queimaduras de quarto grau são profundas e se estendem para os ossos, tendões, ligamentos, músculos, 
não apresentam dor, porém são potencialmente fatais, em decorrência da destruição completa das terminações nervosas (CARBONI RM, et al., 2019; CONITEC, 2018; DA SILVA AV, et al., 2020).

A avaliação da causa, profundidade e extensão, em conjunto com idade, presença de politraumas, comorbidades e outros acometimentos sistêmicos estabelecerão a gravidade do caso. No que tange à profundidade da lesão, têm indicações cirúrgicas as lesões a partir de segundo grau profundo, a fim de minimizar sequelas funcionais e estéticas, como a perda de função local, dor, limitação de movimentos e a formação de cicatrizes hipertróficas ou queloides (FILHO AG, et al., 2012; MOLINA VANA LP, et al., 2020).

A partir desse pressuposto, deter-se de conhecimentos fisiopatológicos auxilia em maiores informações acerca de procedimentos e de materiais idealizados na terapêutica, com o objetivo de reduzir prejuízos e, assim, restaurar a lesão. No entanto, vale destacar que não existe um tratamento "ideal" para casos de queimaduras, mas sim uma gama de terapias que se encaixam a cada circunstância. Primeiramente, devese priorizar a terapêutica funcional e posteriormente os aspectos estéticos, porém, quando possível deve ser realizado um tratamento conjunto entre funcionalidade e estética (FILHO AG, et al., 2012; MOLINA VANA LP, et al., 2020).

Diante disso, posterior à estabilização do queimado, prioriza-se o manejo cirúrgico da ferida. Dessarte, o objetivo da terapêutica cirúrgica é restituir funcional e esteticamente o segmento acometido, a partir da remoção precoce de tecido necrótico, da cobertura da área ferida e da monitorização de perfusão tecidual (CONITEC, 2018).

\section{Desbridamento cirúrgico}

Este procedimento deve ser realizado no centro cirúrgico e tem como objetivo remover tecidos necróticos (epiderme/derme) e secreções, com objetivo de limpar a ferida e preparar o leito para cobertura. É indicado majoritariamente para casos de queimaduras de segundo e terceiro graus. A ferida debridada deve ser protegida por um curativo aberto ou fechado e ambos os curativos têm como objetivo evitar perdas hidroeletrolíticas, proliferação microbiana e devem promover epitelização adequada da área (SANTOS ICRV, et al., 2013; POSSAMAI L, et al., 2018).

\section{Fasciotomia}

Estas se tornam necessárias quando ocorre um acúmulo de sangue ou de fluidos em um compartimento (espaço osteo-miofascial fechado). Isso pode resultar em um aumento de pressão compartimental. Dessa maneira, quando o paciente se queixar de dores progressivas e persistentes, parestesia, e possuir histórico de queimadura (sobretudo de origem elétrica) ou politraumas, a fasciotomia é indicada; a fim de evitar comprometimentos vasculares e mioneurais extensos com consequente isquemia. $\mathrm{O}$ médico, então, deve realizar o procedimento com intuito de salvar membros e de liberar esta pressão interna (POSSAMAI L, et al., 2018; CANHA MI e MARQUES JA, 2016).

\section{Escarotomia}

Diferente da fasciotomia, que é indicada para tratar síndrome compartimental e, portanto, implica na incisão de camadas fasciais; a escarotomia é indicada para queimaduras de segundo e de terceiro graus e consiste na incisão da escara. Essas incisões são realizadas em áreas circulares dos tórax ou de membros superiores ou inferiores, a fim de minimizar danos em estruturas próximas e de aliviar vasos e nervos comprimidos pelo edema e constrição. Deve ser avaliada a coloração da pele, sensação, pulsos periféricos e, sobretudo, a oximetria dos dedos da mão e dos pés para verificar se existe fluxo sanguíneo suficiente (NOVAES FN, et al., 2008; BOLGIANI AN e SERRA MCVF, 2010).

\section{Excisão}

Essa manobra é indicada para queimaduras de terceiro grau ou lesões de segundo grau profundo que acometeram camadas sequenciais ou que evoluíram com infecção. O objetivo desta manobra é remover tecidos desvitalizados até que se obtenham tecidos viáveis; para que seja possível realizar a enxertia. Tal procedimento deve ser realizado logo após 48 a $72 \mathrm{~h}$ da queimadura, após controle do estado vital do paciente, uma vez que estes procedimentos ocasionam perda sanguínea significativa. A excisão é realizada conforme 
a extensão e profundidade da área acometida. Desse modo, quanto mais profunda a lesão, mais tecidos adjacentes são retirados, desde as camadas tangenciais às lesões, até a gordura ou a fáscia. Com isso, após a realização da excisão, a região deve ser imediatamente coberta, ou com enxertia ou com substitutos artificiais de pele (NOVAES FN, et al., 2008; POSSAMAI L, et al., 2018).

\section{Enxertos}

Enxerto é a transferência de um tecido de um local para outro do corpo de um mesmo organismo; ou este pode ser fornecido por organismos distintos. Os enxertos podem ser classificados a partir da fonte de obtenção, colocando em questão: doador e receptor. Dessa forma, são classificados de autoenxertos/autólogos aqueles em que doador e o receptor são o mesmo indivíduo. Os aloenxertos/homólogos são aqueles em que doador e receptor são diferentes, porém são da mesma espécie. Acrescenta-se ainda os enxertos heterólogos/xenoenxertos, os quais doador e receptor são de espécies distintas (LOFÊGO FILHO JA, et al., 2006).

Na procura da escolha ideal de enxertos, a primeira opção deve ser a fonte autóloga, em uma escala sequencial, posterior a esta, opta-se pelo uso da pele homóloga, da heteróloga e, por fim, é estabelecido o uso de substitutos cutâneos. Na prática, os autoenxertos são mais utilizados, devido à comodidade, segurança, baixo custo e capacidade de cobertura definitiva (NOVAES FN, et al., 2008; CARVALHO AFR, 2015).

A partir desse pressuposto, os enxertos de pele são indicados para defeitos cutâneos, no qual o fechamento tecidual não pode ser realizado, sendo indicado para traumas de terceiro grau. Estes podem ser realizados posteriormente à excisão ou mais tardiamente, em lesões que evoluíram com tecido de granulação (NOVAES FN, et al., 2008).

\section{Substitutos cutâneos}

Caracteriza-se como substitutos cutâneos um grupo heterogêneo diverso que abrange desde materiais biológicos até sintéticos. Consideram-se substitutos dérmicos alo e xenoenxertos e, também, matrizes dérmicas. Estes substitutos são usados quando ocorre a escassez de enxertos autógenos, sendo a área doadora cutânea incapaz de cobrir a área lesada. Estes materiais têm por objetivo apresentar a maior biocompatibilidade à pele humana e são utilizados com intuito de cobrir temporária ou permanentemente as lesões (FERREIRA MC, et al., 2011).

Dentre as propriedades de um substituto cutâneo ideal, deve-se listar a importância de se deter de um material semelhante à pele humana; além de custo/benefício adequado, ampla disponibilidade e resistência na perda de propriedades do material quando submetido aos protocolos de desinfecção e de esterilização (FERREIRA MC, et al., 2011; ROA GUTIÉRREZ RER e BARRAGÁN JLP, 2020). Mundialmente o mercado de substitutos cutâneos dispõe de uma grande variedade destes materiais, de modo a depender de cada caso clínico para escolha de um. Diante dessa diversidade, neste artigo serão tratados dois exemplos de substitutos cutâneos, um temporário e outro definitivo (ROA GUTIÉRREZ RER e BARRAGÁN JLP, 2020).

\section{Substituto cutâneo temporário}

Devido aos estudos em ascensão sobre este material e ao custo acessível, o uso da Pele de Tilápia é apontado como uma tecnologia promissora na área da Queimadura. O método de aplicação da pele da tilápia do Nilo (Oreochromis niloticus) como curativo biológico temporário em queimaduras foi realizado primeiramente no Brasil por pesquisadores do Núcleo de Pesquisa e Desenvolvimento de Medicamentos da Universidade Federal do Ceará (DA SILVA AV, et al., 2020).

Nesse estudo, evidenciou-se que esse biomaterial possui semelhanças microscópicas à estrutura morfológica da pele humana, pois a derme do peixe é composta por feixes de colágeno organizados (predominantemente tipo I), compactos e longos, em disposição tanta paralela/horizontal quanto transversal/vertical. Acrescenta-se que a pele também apresentou alta resistência e extensão à tração em quebra (MIRANDA MJB e BRANDT CT, 2019). 
Além disso, para o uso da pele animal como curativo oclusivo, é necessário que seja feito rígido protocolo de desinfecção e esterilização; de maneira que quando submetida a tais processos, a pele de tilápia não apresentou variações quanto à estrutura microscópica e tensiométrica. Isso é importante no processo de cicatrização da área lesada, pois colabora na orientação e na definição dos tecidos (LIMA-JÚNIOR EM, et al., 2017; MIRANDA MJB e BRANDT CT, 2019).

Deve-se mencionar que a produção de tilápia representa aproximadamente metade da produção total de peixes do Brasil, sendo 45,4\%; diante disso, a pele é o subproduto de descarte. A partir dessa informação, destaca-se a fácil obtenção do material; fato que o configura como um produto de fácil aquisição, armazenamento e estabilidade prolongada, além de ser um tratamento de baixo custo (LIMA-JÚNIOR EM, et al., 2017).

\section{Substituto cutâneo permanente}

A Matriz de Regeneração Dérmica (MRD) é um substituto cutâneo biossintético permanente, sendo um material desenvolvido com o objetivo de promover a regeneração coordenada da pele, a partir da equivalência dérmica e epidérmica; uma vez que é composto por uma matriz colágena (correspondente dérmico) e uma camada de silicone (correspondente epidérmico). Dessa maneira, a MRD pode ser empregada nas queimaduras de segundo grau superficial e profundo (PEREIMA BLW, et al., 2011; FREITAS MJLP, et al., 2013).

Primeiramente, é integrada a matriz de colágeno à ferida com a formação da neoderme e após a maturação da matriz a qual ocorre em torno do $21^{\circ}$ dia da queimadura, a camada de silicone é retirada; em seu lugar é realizado um autoenxerto com pele disponível. No entanto, evidenciou-se que devido ao longo tempo de espera para maturação da matriz, a área torna-se mais suscetível a evoluir com complicações (PEREIMA BLW, et al., 2011; DA SILVA AV, et al., 2020).

Diante do relatado, a MRD não vem sendo utilizada sozinha, mas sim associada a Curativos de Pressão Negativa (CPN), os quais apresentam o efeito potencializador da matriz, pelo fato de estimular a absorção de transudatos, a migração endotelial e a angiogênese local; e por reduzir infecções e o tempo de maturação da matriz dos bordos da ferida devido à aproximação (ALDUNATE JLCB, et al., 2012; FREITAS MJLP, et al., 2013; DA SILVA OLIVEIRA ME, et al., 2014).

O CPN compreende a criação de um sistema selado sob o qual é aplicada uma pressão. Assim, esse curativo é formado pela aplicação de uma esponja estéril no local do trauma, sucedida pela fixação de um envoltório de plástico adesivo sobre a esponja; com a inserção do plástico é gerado um sistema selado sob o qual é aplicada, de forma contínua, uma pressão subatmosférica através de um tubo rígido conectado a um aspirador. A substância aspirada é colhida em um recipiente. Assim, o uso da MRD associado ao CPN tem evidenciado menores taxas de complicações, melhor tolerância à matriz e ao enxerto de pele; configurando evolução clínica positiva (PEREIMA BLW, et al., 2011; DA SILVA AV, et al., 2020).

\section{Tratamento multidisciplinar}

O tratamento de queimaduras deve envolver os profissionais de diversas áreas da saúde, sendo eles, geralmente, os cirurgiões plásticos, psicólogos e terapeutas ocupacionais. O atendimento psicológico é de suma importância no tratamento como um todo; uma vez que estes profissionais além de tentarem alinhar expectativas do paciente com todos os tratamentos envolvidos, auxiliam também no processo de superação da experiência traumática (NOVAES FN, et al.,2008; GONÇALVES N, et al., 2011; MOLINA VANA LP, et al., 2020).

Ademais, o papel de é do terapeuta ocupacional é de sua importância, pois ele atua tanto no pré quanto no pós-operatório. No pré-operatório, este profissional auxilia na reabilitação do indivíduo para que atividades diárias sejam desempenhadas com satisfação. Logo após a cirurgia, os terapeutas ficam responsáveis pela confecção de órteses, aparelhos que ajudam a posicionar partes/membros que foram acometidas, evitando deformidades e insuficiências funcionais (MOLINA VANA LP, et al., 2020).

A cosmiatria é um tratamento extra no que tange às terapêuticas fornecidas para as injúrias causadas pela queimadura. Esse tratamento pode ser proporcionado com cremes, lasers e luz pulsada, de forma a colaborar 
com alguma mudança cicatricial ou com a mudança no aspecto da pele, caso desejado. Esse recurso pode ser iniciado durante o tratamento cirúrgico ou logo após o pós-operatório (MOLINA VANA LP, et al., 2020).

\section{CONSIDERAÇÕES FINAIS}

Depreende-se, a partir do exposto, que as queimaduras são acidentes comuns, as quais podem causar danos psicológicos e danos físicos nos mais variados graus de comprometimento aos tecidos. A função do médico é restaurar a funcionalidade e o aspecto estético da área; para isso, deve-se deter de amplo conhecimento da fisiopatologia da queimadura e dos aspectos específicos de cada caso -como idade do paciente, extensão, profundidade, entre outros-, para assim, escolher a melhor opção de tratamento, com vistas a alcançar uma melhor recuperação da lesão.

\section{REFERÊNCIAS}

1. ALDUNATE JLCB, et al. Uso de matriz dérmica associado ao curativo por pressão negativa na abordagem da contratura em pacientes queimados. Revista Brasileira de Cirurgia Plástica, 2012; 27 (3): 369-373.

2. BOLGIANI AN, SERRA MCVF. Updating in the local treatment of the burns. Rev Bras Queimaduras, 2010; 9(2): 3844.

3. FILHO AG, et al. Cartilha para tratamento de emergência das queimaduras. 2012. Disponível em: https://bvsms.saude.gov.br/bvs/publicacoes/cartilha_tratamento_emergencia_queimaduras.pdf.Acesso em: 31 mar. 2021.

4. CANHA MI, MARQUES JA. Síndroma compartimental aguda ou das locas: Conceitos essenciais. 2016. Disponível em: https://rihuc.huc.min-saude.pt/handle/10400.4/1934. Acesso em: 31 mar. 2021.

5. CARBONI RM, et al. Therapy for patients with burns-an integrating review. Revista da Associação Médica Brasileira, 2019; 65(11): 1405-1412.

6. CARVALHO AFR. Enxertos cutâneos: aplicações em cirurgia dermatológica. 2015. Tese de Doutorado.

7. COMISSÃO NACIONAL DE INCORPORAÇẢO DE TECNOLOGIAS NO SISTEMA ÚNICO DE SAÚDE (CONITEC). Membrana de Biocelulose no tratamento de: lesões cutâneas com perda de pele, úlceras venosas e arteriais, lesões por pressão, queimaduras de segundo grau e áreas doadoras de enxerto; Ministério da Saúde. 2018: № 328. Disponível em: http://conitec.gov.br/images/Relatorios/2018/Relatorio_CurativoBiocelulose.pdf. Acesso em: 31 mar. 2021

8. DALMEDICO MM, et al. Hyaluronic acid covers in burn treatment: a systematic review. Revista da Escola de Enfermagem da USP, 2016; 50(3): 522-528.

9. DA SILVA AV, et al. Terapias aplicadas no tratamento das lesões por queimaduras de terceiro grau e extensão variável: revisão integrativa. Medicina (Ribeirão Preto),2020; 53(4): 456-463.

10. DA SILVA OLIVEIRA ME, et al. Curativo de pressão negativa associado à matriz de regeneração dérmica: análise da pega e do tempo de maturação. Rev Bras Queimaduras, 2014; 13(2): 76-82.

11. EVERS LH, et al. A biologia das queimaduras. Dermatologia experimental, 2010; 19(9): 777-783.

12. FERREIRA MC, et al. Substitutos cutâneos: conceitos atuais e proposta de classificação. Revista Brasileira de Cirurgia Plástica, 2011; 26(4): 696-702.

13. FREITAS MJLP, et al. Diminuição do tempo de maturação de matrizes de regeneração dérmica quando associados a uso de curativos de pressão negativa. Revista Brasileira de Queimaduras, 2013; 12(3): 145-152.

14. GONÇALVES N, et al. Fatores biopsicossociais que interferem na reabilitação de vítimas de queimaduras: revisão integrativa da literatura. Rev Latino-Am Enfermagem, 2011; 19(3): 09.

15. LIMA-JÚNIOR EM, et al. Uso da pele de tilápia (Oreochromis niloticus), como curativo biológico oclusivo, no tratamento de queimaduras, 2017; 16(1); 7-10.

16. LIU HF, et al. History and advancement of burn treatments. Annals of plastic surgery, 2017; 78(2): S2-S8.

17. LOFÊGO FILHO JA, et al. Enxertia de pele em oncologia cutânea. Anais brasileiros de dermatologia, 2006; 81(5): 465-472.

18. MIRANDA MJB, BRANDT CT. Xenoenxerto (pele da Tilápia-do-Nilo) e hidrofibra com prata no tratamento das queimaduras de II grau em adultos. Rev. bras. cir. plást, 2019; 34(1): 79-85.

19. MOLINA VANA LP, et al. Atualização e sistematização de sequelas em queimaduras. Cirugía Plástica IberoLatinoamericana, 2020; 46: 97-106.

20. NOVAES FN, et al. Queimaduras-parte II: Tratamento da Lesão.2008. Disponível em: https://www.saudedireta.com.br/docsupload/1331321259083a.pdf. Acesso em: 31 mar.2021.

21. PEREIMA BLW, et al. Curativo com pressão negativa e matriz de regeneração dérmica: uma nova opção de tratamento para feridas extensas. Revista Brasileira de Queimaduras, 2011; 10(3): 78-84.

22. POSSAMAI L, et al. Queimaduras-manejo cirúrgico. Biblioteca Virtual de Saúde, 2018. Disponível em: https://docs.bvsalud.org/biblioref/2018/02/879485/queimaduras-manejo-cirurgico.pdf. Acesso em: 31 mar. 2021.

23. ROA GUTIÉRREZ, PINEEROS BARRAGÁN JL. Coberturas transitorias en quemaduras. Cirugía Plástica IberoLatinoamericana, 2020; 46: 17-22.

24. ROWAN MP, et al. Burn wound healing and treatment: review and advancements. Critical care, 2015; 19(1): 1-12.

25. SANTOS ICRV, et al. Desbridamento cirúrgico e a competência legal do enfermeiro. Texto \& Contexto-Enfermagem, 2013; 22(1): 184-192.

26. SCHAEFER TJ, SZYMANSKI KD. Burn Evaluation and Management. Stat Pearls. 2019.

27. WURZER P, et al. The use of skin substitutes and burn care-a survey. Journal of Surgical Research, 2016; 201(2): 293-298. 